\title{
Asean Dalam Mendorong Negara Permanent 5 Untuk Mengaksesi Southeast Asian Nuclear Weapon Free Zone (Seanwfz)
}

\author{
Seftina Kuswardini \\ Universitas AMIKOM Yogyakarta \\ seftina@amikom.ac.id
}

\begin{abstract}
This paper contains the dynamics of the establishment of nuclear weapons free zone form by ASEAN in the form of SEANWFZ treaty as an effort to maintain regional security of Southeast Asia. But in its implementation there are some obstacles and the most seats is the approval of the State Permanent 5 (P5). The five countries continue to delay reviewing the contents of the agreement until there are several reservations in the form of application zone, ship transit rights, sovereignty and negative security guarantees. Moreover, the problem of coverage of the region consisting of Exclusive Economic Zone (ZEE) of several ASEAN countries in the view is not yet clear related to claim of South China Sea. ASEAN continues to push the five nuclear states in a period of less than two decades by way of negotiation and dialogue. But in essence it will explain the dynamics of SEANWFZ itself, the various reservations that make P5 not willing to access SEANWFZ and the South China Sea settlement as one of the efforts in encouraging China and some P5 countries to access SEANWFZ.
\end{abstract}

Keywords : ASEAN, P5, SEANWFZ,

\section{treaty Abstrak}

Tulisan ini berisi tentang dinamika pembentukan kawasan bebas senjata nuklir yang dibentuk (dibentuk) oleh ASEAN dalam bentuk traktat SEANWFZ sebagai upaya untuk menjaga keamanan regional Asia Tenggara. Namun pada implementasinya terdapat beberapa hambatan dan yang paling kursial yaitu persetujuan dari Negara Permanent 5 (P5). Kelima Negara tersebut terus menunda untuk mengkaji lebih dalam lagi isi-isi dari perjanjian hingga 
timbul beberapa reservasi berupa zona aplikasi, hak transit kapal, kedaulatan dan jaminan keamanan negatif. Terlebih lagi masalah cakupan wilayah yang terdiri dari Zona Ekonomi Ekslusif (ZEE) beberapa Negara ASEAN dianggap belum jelas terkait klaim Laut China Selatan. ASEAN terus mendorong kelima Negara pemilik nuklir tersebut dalam kurun waktu kurang lebih dua dekade dengan cara negosiasi dan dialog. namun pada intinya tulisan ini akan menjelaskan tentang dinamika SEANWFZ sendiri, berbagai reservasi yang membuat P5 belum bersedia mengaksesi SEANWFZ dan penyelesaian Laut China Selatan sebagai salah satu upaya dalam mendorong China dan beberapa Negara P5 untuk mengaksesi SEANWFZ.

Kata kunci : ASEAN, P5, SEANWFZ, traktat

\section{PENDAHULUAN}

Kawasan bebas nuklir mulai menjadi perdebatan negara-negara ASEAN sejak tahun 1970 dan pada saat itu ASEAN masih terdiri dari lima negara yaitu Indonesia, Malaysia, Singapura, Thailand, dan Filipina. Kelima negara tersebut sedang mengupayakan pembentukan proposal ZOPFAN (Zone of Peace, Freedom and Neutrality) untuk Asia Tenggara. ZOPFAN sendiri bertujuan untuk menjaga kawasan Asia Tenggara bebas dari segala bentuk campur tangan atau intervensi dari pihak luar serta memperluas kerja sama di antara negara-negara di Asia Tenggara. Pada saat itu juga ASEAN mengamati beberapa kawasan yang sudah menerapkan kawasan bebas nuklir seperti Amerika Latin, Karibia dan Afrika lalu timbullah inisiatif untuk menerapkan kawasan bebas senjata nuklir di wilayah Asia Tenggara sebagai bagian dari realisasi ZOPFAN (Alagappa, 1987).

SEANWFZ (ASEAN Nuclear Weapon Free Zone) berisi ten- tang kesepakatan yang terdiri dari larangan kepada Negara-negara anggota ASEAN untuk mengembangkan, memproduksi, menguasai dan membeli senjata nuklir, membeli dan melakukan uji coba senjata nuklir di dalam maupun di luar kawasan Asia Tenggara, menerima atau meminta bantuan dari negara mana pun yang berkaitan dengan nuklir serta menjual materi atau bahan pembuat nuklir. Traktat SEANWFZ bertujuan 
untuk menciptakan perdamaian kawasan dan global dalam bidang pelarangan pelucutan senjata nuklir agar tercipta perdamaian dan rasa aman tanpa kecurigaan satu sama lain. ASEAN sangat mengupayakan traktat tersebut ke tingkat Internasional dengan cara diakuinya traktat tersebut melalui resolusi umum majelis PBB 10 Januari 2008 (Fadli, 2014).

Pada tahun 1970 Majelis PBB mengesahkan pasal sebagai izin pembentukan kawasan bebas senjata nuklir dan menegaskannya pada tahun 1975 bahwa pembentukan kawasan bebas nuklir tersebut bertujuan untuk pengontrolan senjata pemusnah masal tersebut agar digunakan untuk tujuan damai. Pembentukan kawasan bebas nuklir termasuk dengan pembentukan perjanjian dan protokol terhadap lima negara pengembang nuklir yang diakui oleh lembaga NonProliferation Treaty (NPT) China, Prancis, Rusia, Inggris, dan Amerika Serikat) untuk ditandatangani dan diratifikasi oleh kelima negara tersebut. Protokol tersebut mengikat secara hukum bahwa negara-negara pengembang nuklir harus menghormati kawasan tersebut untuk tidak menggunakan dan mengancam negara atau kawasan tersebut menggunakan senjata nuklir dan juga tidak bekerja sama elalui jalur apapun dalam hal-hal yang berhubungan dengan senjata nuklir (Kelsey, 2014).

Berkembangnya isu kepemilikan dan pengembangan senjata nuklir oleh negara-negara super- power yang mengakibatkan per- imbangan kekuatan diantara negara-negara pengembang tersebut ASEAN semakin mendorong terlaksananya SEANWFZ ini walau- pun implementasinya berjalan cukup memakan waktu dari mulai disepakati hingga terselesakainnya traktat dan protokolnya. Namun dalam proses implementasinya terdapat kendala dan hambatan yang dihadapi ASEAN, salah satunya yaitu tidak mudahnya persetujuan kelima negara pengembang nuklir yang diakui oleh NPT (Nuclear Non-Proliferation Treaty) untuk menandatangani protokol dan meratifikasinya.

\section{PEMBAHASAN}

\section{Perkembangan Seanwfz}

Pada dasarnya ASEAN ingin berkontribusi dalam realisasi pelaksanaan prinsip piagam $\mathrm{PBB}$ yaitu menjaga perdamaian dunia dengan membentuk kawasan bebas senjata nuklir. Maka pembentukan kawasan bebas senjata nuklir Asia Tenggara ini merupakan tindakan 
nyata untuk mempromosikan perdamaian internasional melalui perdamaian kawasan. Pembentukan zona bebas nuklir ini juga merupakan bentuk dari komitmen dalam Perjanjian Non proliferasi Nuklir (NPT) dalam mencegah proliferasi senjata nuklir. Tujuan lain dibentuknya kawasan bebas senjata nuklir Asia Tenggara ini juga untuk melindungi wilayah Asia Tenggara dari pencemaran lingkungan dan bahaya yang ditimbulkan atau dampak dari limbah radioaktif dan bahan senjata nuklir lainnya. Berikut ini perkembangan SEANWFZ dari mulai di sepakati oleh seluruh negara anggota.

Dimulai pada tahun 1997, di mana telah disepakati pada tahun ini SEANWFZ mulai berlaku. Negaranegara ASEAN mulai meratifikasi dan menyerahkan dokumen ratifikasi tersebut dan Kamboja merupakan- negara ke delapan yang meratifikasi SEANWFZ. Pada bulan juni Perjanjian Bangkok ini mulai didaftarkan kepada PBB. Dan pada tahun tersebut juga dimulainya konsultasi dengan kelima negara pemilik nuklir tentang rencana dari pemberlakuan kawasan bebas senjata nuklir Asia Tenggara. Amerika Serikat menolak untuk menandatangi Protokol dengan alasan zona wilayah yang ditentukan dapat menganggu kepentingan negara-negara di luar SEANWFZ.

Pada tahun 1998 tepatnya 25 Juli, pada Pertemuan Tingkat Menteri ASEAN ke-31 para menteri luar negeri ASEAN mencatat laporan dari pejabat senior ASEAN tentang kemajuan yang dijalankan oleh Kelompok Kerja ASEAN pada ZOPFAN dan SEANWFZ mengenai konsultasi dengan negara pemilik nuklir (P5) dalam konteks penandatanganan protokol pada perjanjian. Para menteri luar negeri menegaskan bahwa penandatanganan protokol oleh negara P5 merupakan manifestasi dari dukungan mereka untuk pelucutan senjata nuklir dan zona nuklir bebas senjata. Mereka menyatakan pandangan bahwa uji coba nuklir oleh India dan Pakistan tidak kondusif untuk merealisasikan perjajian secara penuh (AMM 2012).

Selanjutnya pada tahun 1999, menteri luar negeri ASEAN mengadakan sidang komisi SEANWFZ untuk pertama kalinya. Di dalam sidang pertama tersebut komisi SEANWFZ menyusun draft prosedural dan inisiasi tindakan yang akan dilakukan sesuai dengan perjanjian, termasuk melakukan konsultasi dengan kelima negara pemilik nuklir sampai mereka 
bersedia menerima SEANWFZ dan juga dengan pihak IAEA. Sidang komisi tersebut digelar bertepatan dengan ASEAN Regional Forum (ARF) di Singapura. Pada November China menyatakan kesediaannya untuk mendukung SEANWFZ pada pertemuan informal ASEAN+1. Tahun 2000 ASEAN masih terus melakukan konsultasi dengan negara pemilik nuklir dan IAEA (AMM 2012).

Pada tahun 2001, komisi SEANWFZ memberikan laporannya terkait konsultasi dengan lima negara pemilik nuklir pada forum pertemuan menteri di ARF yang ke8. Pertemuan antara pihak SEANWFZ dan negara P5 berlangsung pada 19 Mei di Hanoi. ASEAN juga melakukan dialog dengan China terkait implikasi SEANWFZ terhadap kedaulatan di Laut China Selatan. Setelah mendapatkan kesepakatan dengan China, ASEAN melakukan konsultasi lebih lanjut dengan ke empat negara lainnya yaitu Rusia, Perancis, Inggris dan Amerika Serikat untuk membahas tentang jaminan keamanan negatif. Dan konsultasi dengan pihak IAEA terus dilakukan untuk menjalankan pasal 5 dalam perjanjian (AMM 2012).

Pada tahun 2002, di pertemuan ASEAN Regional Forum (ARF) yang ke-9 pada tanggal 31 Juli terjadi pertemuan antara pihak SEANWFZ dengan negara pemilik nuklir (P5). Mereka membahas tentang implementasi SEANWFZ dan konsultasi mengenai penandatangan Protokol. Lalu pada tahun 2004, China menyatakan kembali ke- sediannya untuk mendukung SEANWFZ dan ASEAN berusaha untuk menyiapkan waktu untuk pennadatanganan Protokol. Hal tersebut disampaikan pada per- temuan Menteri ASEAN yang ke-37 di Jakarta (AMM 2012).

Dan di tahun 2005, pada pertemuan ke-12 ASEAN Regional Forum (ARF) di Vientiane pada tanggal 26 Juli para Menteri ASEAN menyatakan bahwa kawasan bebas senjata nuklir semakin dipertimbangkan- sebagai upaya untuk mendukung penghapusan proliferasi nuklir di dunia. Hal itu dinyatakan untuk mengingatkan akan pentingnya untuk terus melakukan konsultasi dengan negara P5 sampai kelima negara tersebut bersedia menandatangani Protokol SEANWFZ (AMM 2012).

Pada tahun 2006, para Menteri ASEAN mengeluarkan pendapat bersama yang berisi tentang pentingnya penguatan usaha untuk mendorong negara P5 menandatangani Protokol. Mereka 
mengingatkan tentang isi pasal 20 yang menyatakan bahwa sepuluh tahun setelah perjanjian ini berlaku, diwajibkan untuk mengadakan pertemuan Komisi Eksekutif SEANWFZ untuk meninjau kembali pengoperasian perjanjian.

Pada tahun 2007 tepatnya tanggal 29 Juli, para Menteri ASEAN melakukan pertemuan di Manila, Filipina untuk meninjau tentang pelaksanaan perjanjian dan rencana tindakan yang akan dilakukan untuk menuntun implementasi perjanjian di masa depan. Pertemuan menghasilkan Joint Statement dan Plan of Action (2007-2012) yang berisi tentang pemenuhan komitmen di bawah perjanjian dan aksesi pengamanan IAEA, mengejar konsultasi dengan lima negara pemilik senjata nuklir untuk ratifikasi protokol perjanjian, menjalin kerjasama dengan badanbadan internasional dan regional dalam mengembangkan kerangka hukum untuk memenuhi standar internasional tentang keselamatan nuklir dan membangun jaringan regional untuk pemberitahuan awal dari kecelakaan nuklir.

Pada tahun 2008, pertemuan Tingkat Menteri ASEAN ke-41 telah disepakati untuk menjadikan Thailand sebagai ketua komisi SEANWFZ dan merencanakan untuk kembali memanggil perwailan negara pemilik nuklir (P5) sesegera mungkin. Dan di tahun 2009, ASEAN masih terus mengingatkan negara pihak untuk turut serta dalam mendorong kelima negara pemilik Nuklir agar bersedia menandatangani Protokol SEANWFZ dengan membangun hubungan baik dan kerjasama.

Tahun 2010, terjadi konferensi kedua dari pihak negara pihak dan negara pemilik nuklir untuk melakukan kerja sama pemberlakuan kawasan bebas senjata nuklir Afrika. Hal tersebut membuat ASEAN untuk terus optimis mendorong pihak P5 agar SEANWFZ dapat dijalankan dengan menyeluruh. Dan pada bulan Mei 2010 bertepatan dengan konferensi ke-8 NPT, Menteri Luar Negeri Amerika Serikat Hillary Clinton menyatakan bahwa Amerika siap untuk melakukan konsultasi dengan pihak SEANWFZ untuk mencapai kesepakatan mengenai Protokol SEANWFZ.

Tahun 2011, pada koferensi tahunan Menteri Luar Negeri ASEAN, telah disepakati rencana untuk mengadakan pertemuan langsung yaitu konsultasi informal antara pihak SEANWFZ dan negara pemilik nuklir (P5). Pertemuan tersebut untuk membahas tentang 
kebuntuan selama sepuluh tahun mengenai Protokol SEANWFZ yang belum juga ditandatangani oleh kelima negara tersebut. Peristiwa yang terjadi di Fushima menjadi pertimbangan kepada ASEAN untuk lebih fokus lagi pada tujuan mereka, yaitu menyelesaikan permasalahan kerja sama SEANWFZ dengan negara P5. Dan pada 8 sampai 12 Agustus, untuk pertama kalinya terjadi pertemuan antara negara pihak dan kelima negara pemilik nuklir setelah sepuluh tahun. China masih dengan pernyataan sebelumnya bahwa pihaknya akan menudukung SEANWFZ, namun keempat negara lain yaitu Perancis, Inggris, Rusia, dan Amerika Serikat belum bersedia untuk meratifikasi Protokol SEANWFZ karena masih ingin meninjau kembali mengenai cakupan wilayah yang termaktub dalam perjanjian tersebut (Inventory 2013).

Tahun 2012, pada bulan Januari Kamboja mengirimkan surat kepada kelima negara pe- milik nuklir yang berisi tentang permohonan penandatangan Protol SEANWFZ. Dan pada KTT ASEAN yang ke-20 di Phnom Penh, ASEAN menyatakan bahwa terjadi banyak kemajuan dalam upaya ASEAN untuk merealisasikan kawasan Asia Tenggara menjadi zona bebas senjata nuklir dan ASEAN telah mengajukan dua dokumen kesepakatan dengan China yang terdiri dari nota kesepahaman dan Perjanjian Protokol SEANWFZ. Pada 8 Juli terjadi pertemuan antara Komisi SEANWFZ dengan Menteri Luar Negeri ASEAN yang berakhir dengan penandatangan dari hasil komunikasi berasama antara Komisi SEANWFZ dan negara pemilik nuklir (P5) dan penandatangan nota kesepahaman dengan China. Namun pihak ASEAN menunda penandatangan nota kesepahaman dengan China sampai masalah dengan keempat negara pemilik nuklir lainnya mendapatkan kejelasan (James Martin, 2013).

Pada 10 Juli 2012, kelima negara pemilik nuklir menyatakan belum siap untuk menendatangani Protokol SEANWFZ. Dan pada KTT ASEAN yang ke-21, kesepuluh negara ASEAN menekankan kembali perlunya solidaritas diantara untuk terus berusaha meningkatkan kerjasama keamanan regional salah satunya yaitu merealisasikan SEANWFZ. Selanjutnya pada tahun 2013 sampai 2016, ASEAN mencoba menjalankan rencana kerja yang sudah disepakati alam Plan of Action (2013 -2017) yang salah satunya berisi tentang komitmen negara 
terkait untuk terus mendorong kelima negara pemilik nuklir (Metro, 2016).

Reservasi Negara Permanent 5 Terhadap Seanwfz

Rusia menunda untuk menerima dan meratifikasi SEANWFZ karena ASEAN dianggap kurang konsep dalam membentuk kawasan bebas senjata nuklir. Rusia beranggapan bahwa wilayah KBSN yang ditetapkan oleh ASEAN terlalu luas karena meliputi Zona Ekonomi Ekslusif (ZEE). Selain itu ASEAN masih memiliki konflik wilayah mengenai Laut China Selatan, sedangkan Rusia mempunyai kepentingan ekonomi dengan Laut China Selatan. Alasan Rusia tersebut dikemukakan pada beberapa pertemuan dan pada pertemuan dimana China dan Amerika menyatakan kesediaannya untuk menerima protokol tersebut tiga negara lainnya termasuk Rusia masih belum bisa menyatakan kesepakatan. Menurut Rusia dengan adanya peraturan dalam SEANWFZ yang melarang adanya proliferasi senjata nuklir di wilayah ZEE setiap negara Asia Tenggara tersebut dapat menganggu atau menyalahi hukum United Nations Convention on the Law of the Sea (UNCLOS) yang telah lebih dulu disepakati oleh seluruh negara anggota PBB. Rusia juga membandingkannya dengan KBSN di wilayah lain seperti Amerika Latin, Afrika, Pasifik Selatan dan lainya yang tidak memasukan ZEE ke dalam cakupan batas wilayah pada perjanjian (Hiromichi, 2015).

Menurut Amerika Serikat, dengan adanya SEANWFZ terutama pada poin cakupan wilayah Zona Ekonomi Eklusif (ZEE) dapat menyebabkan permasalahan yang tumpang tindih dengan permasalahan Laut China Selatan yang terdapat beberapa negara ASEAN seperti Brunai, Vietnam, Filipina, Malaysia, Indonesia dan Thailand dengan China yang mana semua negara tersebut saling mengklaim wilayah tersebut. Selain itu Amerika juga masih keberatan mengenai jaminan keamanan negatif yang di tetapkan oleh SEANWFZ (BP, 2016).

Dengan adanya wilayah bebas senjata nuklir khususnya Asia Tenggara Inggris dapat menerima protokol tersebut namun ada beberapa poin yang masih tidak dapat diterima oleh Inggris di dalam protokol tersebut khususnya masalah zona. Inggris menanyakan definisi dari zona itu sendiri dan meminta ASEAN untuk mengkonsepkannya lebih rinci dan masuk akal. Inggris juga mengajukan protes pada 
isi perjanjian pada pasal 7 yang berisikan tentang hak transit kapal dan pesawat udara. Pada pertemuan ASEAN Regional Forum (ARF) tahun 2013 diadakan pertemuan komisi SEANWFZ dengan para perwakilan kelima negara pemilik nuklir, Inggris kembali mengajukan reservasi terhadap protokol tersebut dan meminta ASEAN memberikan jaminan atas seluruh negara di Asia Tenggara untuk benar-benar tidak melakukan ataupun mendukung halhal yang berbau proliferasi nuklir apalagi sampai memiliki nya.

China menyatakan bahwa sangat disayangkan jika zona bebas senjata nuklir tersebut dapat mempengaruhi kedaulatanya atas wilayah, Zona Ekonomi Ekslusif dan landas kontinen. Selain itu China masih mempertimbangkan adanya masalah Laut China Selatan yang melibatkan beberapa negara di Asia Tenggara dan itu sangat berkaitan dengan cakupan wilayah yang telah di tentukan dalam protokol SEANWFZ tersebut. Menurut China sangat sulit menjalankan dan menyepakati protokol ini dengan masalah Laut China Selatan yang diketahui belum terselesaikan tentang permasalahan saling klaim satu sama lain antara beberapa negara di Asia Tenggara (Prasasta,
2016).

Pada Agustus 2013, ber- tepatan pada saat Menteri Luar Negeri Perancis mengadakan kunjungan ke Indonesia Lurent Fabious mengungkapkan bahwa pembentukan Kawasan Bebas Senjata Nuklir ASEAN merupakan usaha negara-negara Asia Tenggara yang memberikan signifikansi terhadap non- proliferasi senjata nuklir di dunia. Tetapi Fabious juga menambahkan bahwa Perancis masih akan mengkaji lagi tentang traktat SEANWFZ. Selanjutnya pada agustus 2015 pada pertemuan perwakilan ASEAN dengan Negara P5 di Kuala Lumpur sama seperti Inggris, Perancis masih keberatan berkaitan dengan pasal 7 dari Perjanjian SEANWFZ tentang kapal dan pesawat udara yang hak transit dan lintas nya di serahkan pada masing-masing negara pihak ASEAN (Daily Witness, 2015). Reservasi terbaru yang diajukan oleh Perancis yaitu penambahan pasal yang menjelaskan tentang diperbolehkannya penggunaan senjata nuklir untuk membela diri dari berbagai hal atau ancaman yang dianggap mengganggu keamanan diri (Mukhlisun, 2016). 


\section{Upaya Asean Dalam Mendorong Negara Permanent 5}

Bisa digarisbawahi bahwa terdapat beberapa hambatan yang membuat SEANWFZ belum juga diaksesi oleh Negara P5 yaitu yang paling menonjol dan merepresentasikan sebagian besar dari kelima Negara tersebut adalah mengenai penjelasan cakupan wilayah Zona Ekonomi Eksklusif (ZEE) maisng-masing Negara Asia Tenggara yang mana belum bisa diterima dikarenakan masih dalam konflik klaim Laut China Selatan. Beberapa poin lainnya tentang isu keamanan negatif, zona aplikasi, kedaulatan dan hak transit. Negosiasi yang dilakukan ASEAN memang mengalami pasang surut bahkan sempat terhenti sekitar satu dekade hingga kembali produktif pada tahun 2011.

Pada tahun 2011 terjadi pertemuan antara komisi SEANWFZ dengan perwakilan kelima negara pemilik nuklir di Jenewa pada Agustus dan di New York pada Oktober 2011. Setelah itu ada pertemuan lanjutan yang merupakan rangkaian dari KTT ASEAN ke- 19 yang diadakan di Bali pada tanggal 14 Oktober 2011. Pada pertemuan -pertemuan tersebut ASEAN terus mendorong kelima negara pemilik nuklir agar bersedia menandatangani Protokol SEANWFZ. Namun kelima negara P5 tersebut masih belum bersedia untuk menandatangani Protokol dengan alasan atas reservasireservasi yang mereka ajukan seperti masalah cakupan wilayah yang meliputi zona aplikasi (zone of application), hak transit kapal dan pesawat udara (transit right and port), kedaulatan (sovereignty) dan jaminan keamanan negative (negative security assurance).

Berlanjut pada KTT ASEAN ke20 Juli 2012, ASEAN dan Komisi SEANWFZ kembali menekankan kepada Negara P5 untuk dapat menyepakati SEANWFZ setelah beberapa lama ini terus diberikan waktu untuk mengkaji ulang. Pola seperti ini terus berlanjut pada KTT selanjutnya. Pada pertemuan ASEANRUSIA SOM yang ke-12 di Kuala lumpur tahun 2015 yang bertemakan peningkatan kerja sama keamanan regional dan internasional, ASEAN mengajukan beberapa poin kerjasama kepada Rusia dan salah satunya adalah meminta Rusia dan negara pemilik nuklir lainnya bersedia untuk menandatangani Protokol SEANWFZ. Pada kunjungan Perdana Menteri Inggris David Cameron di Kantor Sekretariat ASEAN 27 Juni 2016, Sekretaris 
Jenderal ASEAN Le Luong Minh kembali mengingtakan Inggris untuk memberikan langkah terbaru terhadap SEANWFZ. Menurut Minh, Cameron memberikan tanggapan yang baik mengenai hal tersebut dan sepakat bahwa menjaga keamanan negara- negara kawasan merupakan upaya untuk menjaga keamanan dunia juga walaupun tidak saat itu juga terjadi proses penandatanganan Protokol SEANWFZ.

Di samping upaya -upaya yang ditempuh ASEAN dalam bentuk negosiasi dalam pertemuan dan dialog tersebut, ada hal lain yang berkenaan dengan konflik Laut China Selatan. SEANWFZ mempunyai hubungan dengan LCS terkait cakupan wilayah yang ditetapkan meliputi ZEE setiap Negara Asia Tenggara yang mana beberapa Negara tersebut masih berselisih paham dengan China yang mana ZEE tersebut meliputi perairan LCS. KTT ASEAN pada Desember 1998 mengahsilkan CoC (Code of Conduct on South China Sea). Kode Etik Konflik di Laut China Selatan ini berupaya membuat aturan larangan berkonflik khususnya bagi negara-negara yang memiliki kepentingan di Laut China Selatan.Kode Etik Konflik di Laut China Selatan ini diharapkan dapat dikembangkan lagi di antara negaranegara ASEAN untuk membuat aturan larangan berkonflik dengan sesama anggota maupun dengan negara mitra di luar kawasan. Selain untuk menyelesaikan konflik, Kode Etik Konflik di Laut China Selatan ini juga diharapkan nantinya dapat mengembangkan kerja sama di Laut China Selatan antar sesama negara anggota maupun dengan negara di luar kawasan ASEAN (Victor, 2015).

Pembentukan Code of Conduct yang di bentuk ASEAN untuk China memang tidak sertamerta langsung dapat membuat permasalahan Laut China Selatan antara China dan beberapa negara Asia Tenggara selesai begitu saja. Tetapi setidaknya tidak membuat permasalahan dan gap diantara mereka menjadi tidak semakin besar sehingga dapat mempengaruhi kerja sama lainnya kususnya dalam bidang keamanan. Selain itu ASEAN juga sedang dalam upaya mengajukan nota kesepahaman perjanjian SEANWFZ dengan China (Victor, 2015).

\section{KESIMPULAN}

Pemberlakuan kawasan bebas senjata nuklir di Asia Tenggara yang bersumber hukum pada SEANWFZ merupakan realisasi ASEAN dalam menciptakan dan menjamin keamanan kawasan. Kesepuluh 
Negara ASEAN telah rampung menandatangani perjanjian sejak tahun 1997, namun SEANWFZ belum dapat dijalankan sepenuhnya karena harus mendapatkan kesepakatan dan komitmen dari Negara Permanent 5 (P5) yang terdiri dari Amerika Serikat, Inggris, Perancis, China dan Rusia. Perjanian tersebut berisi tentang larangan kepada Negara anggota untuk memiliki, memproduksi, memiliki kendali, meperoleh dan mengembangkan senjata nuklir di dalam maupun di luar kawasan Asia Tenggara. Sedangkan Negara P5 dilarang untuk melakukan kegiatan yang berbau proliferasi senjata nuklir disekitar kawasan yang sudah ditetapkan di dalam perjanjian tersebut.

Dorongan terhadap Negara P5 terus dilakukan oleh ASEAN dan komisi SEANWFZ dalam bentuk dialog, pertemuan dan negosiasi semacamnya. Namun semua momen yang diharapkan akan menjadi waktu yang tepat untuk melakukan kesepakatan selalu mengalami penundaan dikarenakan reservasireservasi dari kelima Negara tersebut yang meliputi zona aplikasi, kedaulatan, hak transit kapal, dan jaminan keamanan negatif. Pada zona aplikasi meliputi cakupan wilayah yang mana masih menjadi klaim atas konflik Laut China Selatan. Penyelesaian konflik LCS bisa jadi akan dapat menyelesaikan hambatan yang aksesi P5. Namun pada kenyataannya klaim wilayah LCS belum juga dapat diselesaikan sama seperti Negara P5 yang belum juga bersedia mengaksesi SEANWFZ. Kedepannya ASEAN harus dapat mendorong P5 lebih keras lagi dengan menggunakan cara yang dirasa lebih efektif, karena pemberlakuan kawasan bebas senjata nuklir merupakan komitmen yang harus diwujudkan guna memberikan rasa aman bagi masyarakat ASEAN.

\section{DAFTAR PUSTAKA}

Alagappa, M (1987), Towards a Nuclear-Weapons-Free Zone in Southeast Asia, ISIS Research Note, Kuala Lumpur: Institute of Strategic and International Studies.

Asean close to pact on $\mathrm{N}$-arms ban, Published on14/02/2012 at 12:00 AM, Newspaper section: News, tersedia di http://www.bangkokpost.com/ print/279696/, diakses pada 05 April 2018

ASEAN dan Rusia Canangkan Kerjasama Keamanan Regional dan Internasional, 21 Mei 2015, tersedia di http://elshinta. 
com/news/12536/2015/05/21/ asean- dan-rusia-canangkan $\mathrm{pen}$ in g k at a n - k e r j a - s a $\mathrm{ma}-\mathrm{ke}$ a man a $\mathrm{n}-\mathrm{reg} \mathrm{i}$ o n a 1 - d a n - internasional, diakses pada 10 April 2018

Charles J. Moxley (2011), Nuclear Weapons and Compliance with

International Humanitarian

Law and the Nuclear Non-

Proliferation Treaty, Fordham

International Law Journal.

Crail Peter \& Liang Xiaodon (2012), Southeast Asia Nuclear-Weapon-Free Zone and The Nuclear-Weapon States, Washington D.C, EastWest Center in Washington.

Daily Witness Staff, ASEAN face uphill task in getting nuclear states to sign treaty, 05 August 2015, tersedia di http:// dailywitness.com/focus-aseanfaces-uphill-task-in-getting nuclear-states-to-sign-treaty/ , diakses pada 28 Maret 2018

Donald E. Weatherbee, International Relation In The Southeast Asia, The Rowman \& Littlefield Publishing Group, Inc, United Kingdom, 2009

Erik A. Cornellier (2013), In The Zone: Why The United State Should Sign the Protocol to The Southeast Asia Nuclear Weapon
Free Zone, Pacific Rim Law and Policy Journal.

Evan S. Medeiros (1996), Southeast Asian Countries Agree To Create Nuclear-Weapon-Free Zone, Arms Control Today, Vol. 25, No. 10 , Arms Control Association.

Helle Winge Laursen (2001), An Introduction to the Issue of Nuclear Weapons in Southeast Asia, International Law and Policy Institute.

Hiromichi Umebayashi (2015), tersedia di http://www. peacedepot.org, Diakses pada tanggal 6 April 2018

Join Comminuque the $30_{\text {th }}$ ASEAN Ministerial Meeting (AMM), ASEAN Political-Security Community Document tersedia di http://asean.org/?static_ post=joint - comminuque - the30th-asean-ministerial-meeting -amm-2, diakses pada 01 April 2018

Jonathan L.Black Branch, Nuclear non -Proliferation in International Law Volume 1, Asser Press, United Kingdom, 2014

Jozef Goldblat (1997), Nuclear Weapon Free Zone: A History and Assessment, Download by University of Manchester 
Library, dalam International

Herald Tribune.

Kelsey Davenport (2014), Nuclear Weapon Free Zone (NWFZ) at a glance, May 2012 tersedia di http://www.armscontrol.org/ factsheets/nwfz diakses pada tanggal 2 April 2018

Lionel Yee Woon Chin (1998), Nuclear Weapon Free zones-a Comparative Analysis of The Basic Undertaking in The SEANWFZ Treaty and Their Geographical Scope of Application, Singapore

Journal of International \& Comparative Law.

Michael Hamel Green (2005),

Regional Initiatives on Nuclear and WMD Free Zones Cooperative Approaches to Arms Control and Nonproliferation, United Nations Institute for Disarmament Research (UNIDIR), Geneva Switzerland.

M C Abad Jr (2005), A Nuclear Weapon-Free Southeast Asia and its Continuing Strategic Significance, Institute of Southeast Asian Studies (ISEAS), Contemporary Southeast Asia, Vol. 27, No.2. Menlu Dorong Negara Pemilik Senjata Nuklir Adopsi
SEANWFZ, 24 Juli 2014 tersedia di http://internasional. m e trotvn e w s . com/a $\mathrm{s}$ i a / VNx928yb-menludorong-negara-pemiliksenjata-nuklir-adopsi-seanwfz, diakses pada 29 Maret 2018 Mukhlisun (2013), Syarat Tiga Negara Untuk Seanwfz Masih Dikaji, tersedia di http:// sumbar. antaranews . com/ berita/43420/syarat-tiganegara-untuk-seanwfz-masihdikaji.html, diakses pada 1 April 2018

Southeast Asia Nuclear Weapon Free Zone (Treaty of Bangkok) 2013, Inventory of International Nonproliferation Organizations and Regimes, James Martin Center for Nonproliferation Studies.

United States, Russia, China, French, UK refusing to sign ASEAN Weapon Free Zone Treaty, Nuclear News (the news that matters about the nuclear industry), tersedia dihttp://

nuclearnews.net/2012/07/09/

united-states-russia-chinafrance-uk-refusing-to-signasean- weapons-free-zonetreaty/, diakses pada 02 April 2018

Prasasta Widiadi (2013), Sekjen Asean Hargai Upaya Perancis 
Kerjasama dengan ASEAN, tertuang pada http://www. satuharapan.com/read-detail/

$\mathrm{read} / \mathrm{sekjen-asean-hargai-}$

upaya-prancis -kerja-samadengan-asean, di akses pada 28 Maret 2018

Treaty on The Southeast Asia Nuclear Weapon Free-Zone (2006), Handbook of Selected ASEAN Political Documents, Third Edition, The ASEAN Secretariat, Jakarta.

Victor Maulana (2015), Ini Upaya RI Selesaikan Konflik Laut China Selatan, tersedia di http:// international.sindonews.com/ read/1057189/40/ini-upaya-ri- selesaikan-konflik-laut-chinaselatan-1446104843 diakses pada 4 Mei 2016

Victor Maulana (2015),ASEAN Desak Penyelesaian Laut China Selatan, Berita Internasional Asia Pasifik, tersedia di http:// international.sindonews.com/ read/995886/40/asean-desakpenyelesaian-konflik-lautchina- selatan-1430390752, diakses pada 11 April 2018 
